\title{
Epistemologia da Comunicação na Democracia: a centralidade do conceito de comunicação na análise dos processos políticos
}

\author{
Luiz Signates \\ Professor do PPG em Comunicação \\ da Universidades Federal de Goiás \\ e da graduação em Comunicação da \\ Pontifícia Universidade Católica de \\ Goiás. Coordenador dos Núcleos de \\ Pesquisa em Comunicação, Política \\ e Cidadania (UFG) e Comunicação \\ e Cidadania (PUC). Doutor em \\ Comunicação pela ECA/USP. \\ E-mail: signates@gmail.com.
}

\begin{abstract}
Resumo: As ciências sociais conferem ao conceito de comunicação um lugar secundário, a partir do qual os processos sociais são analisados sem que se dê às institucionalidades e processos comunicacionais a relevância que lhes deve ser conferida, especialmente ao se avaliar as sociedades contemporâneas, altamente capilarizadas pelas tecnologias de comunicação. Este trabalho busca discutir essa problemática e efetua, a partir dela, uma experimentação teórica no campo de contigüidade das ciências políticas, buscando dar à comunicação uma centralidade tal, que se torne fortemente constitutiva da própria noção de democracia.
\end{abstract}

Palavras-Chave: Epistemologia da Comunicação. Comunicação e política.

\begin{abstract}
The Social Sciences set the communication concept down in a secondary place, resulting in an analysis of the social processes without the relevance required by the institucionalities and the communication processes, especially if one evaluates the contemporary societies, highly capillarized by the communications technologies. The present paper proposes to discuss this issue and to provide a theoretical experimentation on the field of Political Sciences' contiguity, aiming at giving to communication a central role, so it can strongly become a constitutive part of the notion of democracy.
\end{abstract}

Keywords: Communication epistemology, communication, politics.

\section{Introdução}

A questão de conferir centralidade ao conceito de comunicação, para a leitura de processos sociais que tenham a ver com o campo científico da comunicação, é uma das mais atuais problemáticas com as quais tem se defrontado a discussão epistemológica da comunicação no Brasil, em especial o GT de Epistemologias da Compós ${ }^{1}$. A busca, nesse sentido, é a de dar ao objeto da comunicação a conformação e a preponderância que configurem uma possibilidade de descrição das realidades sociais capaz de dar alta consideração aos conceitos e categorias de análise dos processos comunicacionais, em seus próprios termos.

Nesse sentido, busca-se, aqui, não apenas consolidar o campo de estudos, mas também trabalhar na perspectiva de tematizar questões de interesse de outros campos científicos - neste caso, o da ciência política - de forma a ressaltar, na interdisciplinaridade construída, a contribuição efetiva do campo da comunicação ao pensamento social como um todo. A compreensão, nesse sentido, é a de destacar que, especialmente no modo como se ordena o mundo contemporâneo, a comunicação constitui um conceito fundamental, que emerge como importante categoria de análise para interpretar os mais variados processos sociais. 
O amplo problema que torna este debate necessário parte do modo como as ciências da comunicação são observadas, pela estruturação da ciência no Brasil hoje. Pelos critérios do CNPq, a comunicação é classificada como "ciência social aplicada". Evidentemente, tal categorização tende a não levar em conta a relevância teórica das ciências da comunicação, como fundamento para as teorias sociais de base e para as ciências que se baseiam no vinculo social, tais como a sociologia, a antropologia, a política e a psicologia.

A classificação do CNPq pode ser avaliada como decorrente do desprestígio teórico da disciplina e da fragilidade política do campo, mesmo na grande área das ciências humanas e sociais. Além disso, o adjetivo "aplicada" parece ser decorrente de uma concepção na qual a comunicação é vista como mera decorrência do pensamento das ciências sociais como um todo, na condição de "aplicação", ou instrumento, dentro de uma perspectiva tendente ao tecnicismo ou à abordagem funcionalista.

Evidentemente, essa concepção procede do próprio modo de funcionamento do campo, especialmente da forma como o ensino de comunicação foi estruturado e das relações, extremamente funcionais, do mundo acadêmico da comunicação com o mercado de trabalho. Os cursos típicos da área, tais como o jornalismo, a publicidade e as relações públicas, são historicamente voltados para o ensino técnico, dentro do qual o desenvolvimento do pensamento teórico, quando não é simplesmente visto como mera perda de tempo, prima pela superficialidade.

A superação desse gap de desenvolvimento teórico, sem perder a dimensão da aplicabilidade prática das diversas formas de comunicação, é um dos desafios do campo científico da comunicação no Brasil hoje. É preciso desenvolver conceitualmente a noção de comunicação, delimitando seu campo de estudos e sua zona de definições, bem como especificar sua racionalidade específica e dimensionar adequadamente o campo metodológico de sua pesquisa. Este trabalho, sem qualquer pretensão exaustiva, pretende ser uma contribuição para a superação desse gap.

Dentro desta problemática, este artigo efetua, primeiro, a crítica da abordagem que as ciências sociais e políticas dão ao conceito, ao tratá-lo de forma subjuntiva e secundária, buscando evidenciar a situação de invisibilidade da comunicação nas disciplinas sociais, para, em seguida, experimentar a aplicação do conceito à dimensão dos estudos da política, e, destarte, buscar a reconstrução da noção de democracia a partir das questões comunicacionais.

\section{Comunicação nas ciências humanas e sociais: a invisibilidade de um conceito}

Ao se dizer que a disciplina e o campo científico da comunicação carecem de afirmação e autonomia, várias coisas de fato estão sendo ditas. A primeira, de natureza conceitual e talvez a mais relevante, é a de que nem mesmo os pensadores da área sabem ao certo o que seja o objeto que dizem estudar. À questão sobre o que significa comunicação, muito se diz, mas pouco se significa, pois, na maioria das vezes, outras teorias, exógenas ao campo, funcionam como base para a construção das definições e dos usos teóricos.

Esta última observação é o mote para a segunda questão: os fundamentos teóricos das ciências da comunicação não se encontram em seu interior. As teorias explicativas vêm dos sistemas teóricos dotados histórica e epistemologicamente de maior prestígio, no campo das ciências humanas e sociais, em especial das áreas da lingüística, da sociologia e da psicologia.

Na verdade, essa condição de exogenia das bases teóricas da comunicação não é um problema em si. Significam, talvez, que os diversos arsenais teóricos das ciências sociais e humanas têm algo a dizer sobre o que ocorre nos processos 
comunicacionais, que se desenvolvem vertiginosamente nas sociedades contemporâneas. Entretanto, o que se questiona, porquanto constitui sintoma da fragilidade teórica do campo da comunicação, é que, sempre que o conceito de comunicação comparece numa dessas descrições teóricas, o processo comunicacional em estudo não exsurge como centralidade daquilo que se estuda, e sim, como subjuntivo, subalterno, na análise feita.

A comunicação, então, não é de fato descrita, ou explicada teoricamente. E sim serve como instrumento para conferir explicação para outros fatores, funcionando como lente para visualizar outros objetos. Essa característica da exogenia dos estudos sobre questões de interesse da comunicação não apenas expressa a fragilidade do campo - o que poderia ser julgado como uma mera e desimportante reivindicação política, fruto do simples anseio dos pesquisadores da área de autoafirmarem suas próprias identidades, na disputa pela legitimidade, no vasto campo das ciências.

A exogenia teórica na verdade expressa um problema muito mais grave: os processos comunicacionais, que talvez se responsabilizem por grande parte das transformações sociais, políticas e culturais do mundo contemporâneo, não são explicadas em seus próprios termos. Caso esteja correto o juízo de que a comunicação é mais do que simples aparato instrumental de outros processos, há que se combater o que pode ser chamado de "invisibilidade" do conceito de comunicação, ante outros conceitos e categorias mais prestigiados ou ante objetos que não sejam o processo comunicacional, mesmo quando valores, relações e instituições de comunicação estejam empiricamente envolvidas.

Um exemplo nítido e quase absurdo, a partir do ponto de vista deste trabalho, para exemplificar esse caráter de invisibilidade teórico-conceitual, encontra-se, sem dúvida, na última grande teoria social produzida no século 20: a Teoria da Ação Comunicativa, de Jürgen Habermas (1981 e 1981a). A enorme e altamente consistente articulação teórica do filósofo alemão foi capaz de produzir uma teoria que trata praticamente de todas as grandes ciências do homem e produz enfim uma teoria geral de sociedade ancorada no conceito de comunicação... sem tratar de mídia, nem de tecnologias de comunicação, nem de relações sociais tecnologicamente mediadas...

O que Habermas denominou "comunicação" foi o vínculo social lingüisticamente mediado, desconsiderando, nesse movimento, o conceito de comunicação, tal como formulado pela ciência específica. A limitação dessa apropriação conceitual é visível, para qualquer pesquisador que trabalhe a centralidade da comunicação como conceito fundamental e categoria de análise para o entendimento dos processos sociais contemporâneos.

Ao desconhecer a comunicação, em seu sentido mais amplo, o autor alemão cometeu o equívoco de submeter as relações sociais ao vínculo estreito e original da relação face-a-face, como já pontuara Thompson (1998), e, também, deixou de perceber os modos de formação das esferas públicas, na medida em que seu modelo não tem praticidade categorial para surpreender as redes de comunicação, ou a linguagem em circulação, na complexa formação de imagens públicas.

Uma sociedade capilarizada por tecnologias de comunicação não pode ser descrita como uma sociedade anterior ao desenvolvimento dessas tecnologias, tal é a transformação social que essas possibilidades, uma vez extensivamente utilizadas pelos sujeitos, para configurarem as próprias relações. Sendo assim, não é viável pretender que as ciências da comunicação prossigam no nível de fragilidade teórica em que se encontram.

Esta é a talvez a tarefa fundamental do campo científico da comunicação, hoje. Como tentativa de contribuição para isso, procurar-se-á evidenciar alguns 
dos elementos epistemológicos e teóricos que, para os efeitos deste trabalho, considera-se fundamentais: o conceito de comunicação e suas peculiaridades aplicativas (no caso em pauta, na relação com a política, em condição não subalterna da articulação teórica) e metodológicas (ou seja, na conformação específica das pesquisas em comunicação, em termos gerais, e da comunicação política, de modo específico).

\section{A comunicação como campo autonomizado da modernidade}

A exigência de uma conformação teórica específica para a comunicação não advém tão somente do tratamento subjuntivo das demais ciências humanas e sociais, quando tratam dos processos e instituições de comunicação. Aliás, esse tratamento talvez seja tão demonstrativo da fragilidade do campo da comunicação, como o é da incapacidade das ciências sociais tradicionais em tratar desse objeto. Mas, a questão não é apenas esta.

Tal necessidade teórica procede do reconhecimento de que algo mudou, na realidade social das sociedades, com o desenvolvimento das tecnologias de comunicação e das redes de relações sociais criadas a partir de então. $O$ que aqui foi chamado de capilarização das tecnologias na intimidade da vida das pessoas parece ser o movimento significativo, que, através de inúmeras modalidades, vem se tornando cada vez mais profundo.

O que parece importante ressaltar é que os processos de comunicação, se antes puderam ser considerados vicários ou instrumentais dos demais campos sociais, ganharam forte autonomização, a partir do desenvolvimento das novas tecnologias de comunicação e toda a institucionalidade que acompanhou esse movimento.

A idéia de autonomização dos campos da modernidade procede de Max Weber (1921). Um campo social qualquer se autonomiza, na medida em que as condições de legitimidade e de referência simbólica para hierarquização dos sujeitos que o compõem advém do interior e das regras do próprio campo, e não externamente. Com base nesse parâmetro e de olho nas características da modernidade, Weber identificou três racionalidades autonomizadas: a racionalidade cognitivoinstrumental da ciência e da filosofia; a racionalidade estético-expressiva das artes; e a racionalidade moral-prática da religião e do Direito (Santos, 1995).

A percepção de que o campo da comunicação se autonomiza foi intensamente trabalhada por Lavina Ribeiro, para quem, na consolidação da esfera pública moderna, a comunicação se institucionalizou em um campo regido por uma normatividade própria. Ora, se isso for verdadeiro, então não é suficiente pensar a comunicação a partir da racionalidade específica dos demais campos, nem mesmo como um processo "vicário" ou "delegado", como teorizou Adriano Rodrigues (1990).

A fim de testar esta possibilidade, pode-se pensar que o campo da comunicação trabalha perpassando as três outras racionalidades. Nesse sentido, encontra-se a racionalidade moral-prática nas dimensões normativa e política da comunicação, abrindo a fecunda possibilidade dos estudos políticos e éticos num momento histórico em que o fazer político implica visibilidade. De forma semelhante, a racionalidade cognitivo-instrumental pode ser encontrada na dimensão cognitiva da comunicação, o que possibilita o estudo não só do funcionamento pedagógico dos meios ou da relação entre comunicação e educação, como também para a apreensão da lógica econômica do funcionamento das instituições desse campo. E, por fim, a racionalidade estético-expressiva seria a que proporciona as possibilidades de abordagem da comunicação como arte. Como se vê, tal abordagem abre vias cuja pertinência não pode, de forma alguma, ser desconsiderada. 
Em face dessas formulações axiomáticas, passa-se aqui ao debate sobre as condições de possibilidade da democracia na comunicação e das relações efetivas, empiricamente analisáveis, entre democracia e comunicação. Este artigo pretende enfeixar alguns corolários das reflexões anteriores, sintetizados em três principais, a saber: primeiro, a comunicação, no plano social, como modo de ser da democracia; segundo, no plano político, a comunicação como garantidora do regime democrático; e, como conseqüência teórica das duas razões anteriores, terceiro e último, no âmbito das práticas governamentais, a comunicação como política pública.

\section{Comunicação como modo de ser da democracia}

O conceito de democracia não é, de forma nenhuma, simples, embora algumas de suas características possam ser considerada quase autoevidentes, tal é a maneira como se conjugam à significação geral ou usual da palavra. As teorias a respeito não são uníssonas, trabalham com diferentes categorias e nem sempre guardam a clareza necessária que permita afirmar, diante de um país, ou governo ou regime qualquer, se ele é ou não democrático. Neste trabalho, dar-se-á preferência a uma sequência simplificada de idéias e argumentações, que, evidentemente, não terá a pretensão de esgotar a temática, nem mesmo nos complexos aspectos em que se delineia no campo das ciências políticas. A pretensão é adotar a abordagem que se mostrar mais sugestiva para que se possa identificar a relação teórica possível entre democracia e comunicação.

O que vem a ser, afinal, a democracia? Raro é o autor que não principie a busca por uma definição consistente na própria etimologia da palavra, cujas origens remetem ao vocábulo grego $\delta \eta \mu o \varsigma$ (demos), isto é, povo. É o que testemunha Guilhermo O'Donnel, ao afirmar que "a palavra democracia, desde tempos imemoriais, recebeu fortes (mas diferentes) conotações morais, todas fundamentadas em uma visão dos cidadãos como agentes" (O'DONNEL, 1999). A priorização do cidadão, do povo, da sociedade ante o Estado e as demais instituições, das bases sociais perante as estruturas de poder, constitui o fundamento inicial do significado de democracia, qualquer seja a teorização a que se venha a recorrer.

Isso, contudo, de modo nenhum é o bastante, caso se considere a complexidade com que se organizam as democracias contemporâneas, permeadas por diferenças e recheadas de contradições, dentro das quais, especialmente na América Latina, elementos modernos se misturam a heranças arcaicas e a liberdade entrecruze o autoritarismo sob as mais variadas formas.

Os teóricos em geral remetem a Schumpeter para definir a democracia a partir de certas regras, no que ele chama de "método democrático", definido como sendo um "arranjo institucional para chegar a decisões políticas pelas quais os indivíduos adquirem o poder de decidir mediante uma competição pelo voto popular" (SCHUMPETER, 1942, p. 242). Esta definição acrescenta a questão institucional obrigatória, embora não exclusivamente, a relação Estado-sociedade - e a técnica do sufrágio.

Outra categoria, de caráter complementar a esta, foi apontada por Adam Przeworski, segundo o qual "democracia é um sistema em que os partidos perdem eleições. Há partidos, ou seja, divisões de interesses, valores e opiniões. Há competição organizada por regras. E há periodicamente vencedores e perdedores." (PRZEWORSKI, 1996, p. 10). O direito ao contraditório e à oposição, e a garantia política e institucional de que o voto popular e livre será respeitado, na decisão pela alternância do poder, constituem fatores básicos de caracterização de um regime democrático, quaisquer sejam suas peculiaridades. 
Seguindo nessa linha, em direção a um nível de detalhamento ainda maior, é digna de nota a extensa definição de Diamond, Linz e Lipset, segundo os quais a democracia é

\begin{abstract}
Um sistema de governo que atende a três condições essenciais: concorrência ampla e significativa entre indivíduos e grupos organizados (especialmente os partidos políticos) para todas as posições de governo que têm poder efetivo, em intervalos regulares de tempo e com exclusão do uso da força; um nível 'altamente includente' de participação política na seleção dos líderes e das políticas públicas mediante, ao menos, eleições periódicas e isentas, de modo a não excluir nenhum grupo social importante dentre a população adulta; e um grau suficiente de liberdades civis e políticas - liberdade de expressão, liberdade de imprensa, liberdade de formar e filiar-se a organizações - para garantir a integridade da competição e da participação política. (DIAMOND, LINZ E LIPSET, 1990, p. 6-7).
\end{abstract}

Ressalte-se, nesta última citação, a presença de alguns elementos altamente relevantes, até para a sustentação das exigências anteriores: a taxa de inclusão, tão grande quanto possível, nos processos competitivos pela liderança; e as diversas liberdades, com destaque às liberdades relacionadas à comunicação - expressão e imprensa. Maior precisão neste caso específico advém de Sartori, segundo o qual "para haver democracia é preciso que exista uma opinião pública autônoma [...] [e uma] estruturação policêntrica da mídia e seu jogo competitivo" (SARTORI, 1987, 98 e 110). Descentralização da propriedade das instituições de mídia e formação de uma opinião pública autônoma são, pois, condições fundantes do processo democrático.

Interessante observar como a comunicação, seja em sua versão institucional e sistêmica, seja como processualidade social de trocas simbólicas, faz-se presente como elemento aferidor da condição democrática. Onde quer que se pense o jogo democrático em funcionamento, pode-se surpreender a comunicação como categoria analítica fundamental. Senão vejamos: é o jogo comunicacional o que torna possível a existência e a administração do contraditório nas disputas eleitorais; a própria figura do voto não é outra coisa senão o modo pelo qual o cidadão emerge como eleitor, ao gerar a informação para o sistema democrático de sua vontade política, em relação às forças em disputa; e, por fim, as condições essenciais de liberdade da fala e da formação de opinião, que constituem direitos humanos universais, mediante os quais a ética democrática se consolida em todos os seus aspectos.

Eis porque se postula neste trabalho que a comunicação não seja observada apenas como um "instrumento" ou uma "ferramenta" pela qual se dá a estratégia política. Essa visão externalizada dos processos de comunicação não apenas é redutora, na medida em que deixa de perceber o sentido estruturante da comunicação na sustentação da democracia. Tal apreensão é igualmente falsa, porquanto não se pode avaliar uma democracia sem considerar as circunstâncias estruturais e conjunturais da comunicação na formação e no relacionamento dos grupos sociais, como também nos modos específicos de desenvolvimento das imagens públicas em circulação.

A comunicação é, pois, não apenas um componente da democracia, mas o seu próprio modo de ser, nas instituições, nos grupos sociais e na sociedade como um todo. Em outras palavras, será tão mais democrática uma sociedade, quanto forem livres e fortes os processos de produção e circulação social do sentidos. E, em contrapartida, será tão mais autoritária e antidemocrática uma sociedade, quanto os modos de comunicação forem reduzidos ao silêncio ou impedidos de circular, pela ação violenta dos sistemas de poder. Somente pela comunicação, a democracia adquire condições de se realizar como tal, na medida em que passe 
${ }^{2} \mathrm{O}$ conceito de "gradiente de democraticidade" constitui uma categoria qualitativa de análise política, a partir da noção de comunicação, e é explicitada em uma obra do autor, ainda inédita, da qual as reflexões deste artigo igualmente fazem parte. a imperar a solução não violenta dos conflitos, ao se tornarem mediados pela linguagem, seja pelo jogo argumentativo, seja pela disputa das imagens, em público.

\section{Comunicação como garantia do regime democrático}

Os aspectos práticos e políticos do primeiro corolário fazem-se sentir com clareza, na exposição deste segundo. Sendo a comunicação o modo de ser da democracia, parece autoevidente que a preservação de uma democracia exige como ação permanente o fortalecimento e a ampliação dos processos de comunicação. Não custa, porém, explicitar esse axioma, a fim de torná-lo mais visível, até para o estudo de suas resultantes metodológicas e categoriais.

Esse raciocínio pode ser feito tanto na análise das condições de existência ou extinção do regime democrático, quanto na avaliação fina dos sinais de democratização - que temos denominado "gradiente de democraticidade" 2 . Democracia não é algo que simplesmente existe ou não existe, e sim um processo, demarcado pela existência em maior ou menor grau de cada uma de suas condições, inclusive e sobretudo as de comunicabilidade entre indivíduos, grupos e instituições entre si.

A história das sociedades contemporâneas já demonstrou, à saciedade, que a ação demarcadora da extinção das democracias, ou seja, que as ações violentas de implantação de ditaduras caracterizam-se, entre outras coisas, pelo silenciamento das instituições e da própria população. O silêncio da sociedade e o controle da comunicação constituem os elementos básicos de garantia do poder totalitário, que, em contrapartida, só se viabiliza se e quando tais elementos perdem, por alguma razão, sua efetividade.

Eis porque as providências típicas de um regime totalitário, no momento em que se impõe pela força, são basicamente três: fechar o parlamento, controlar absolutamente a imprensa e reprimir a formação de toda e qualquer esfera pública. O poder, a efetividade e a capacidade de autosustentação de uma ditadura é diretamente dependente da eficácia dessas providências. Qualquer fratura ou fragilidade em qualquer um desses elementos constitui séria ameaça ao regime e pode, no limite, determinar a criação das condições simbólicas de seu fracasso.

A repressão da esfera pública costuma ocorrer por meio de um atentado direto aos direitos fundamentais de liberdade de expressão e opinião. 0 regime autoritário decreta Estado de exceção e passa a policiar a interação dos grupos e instituições sociais, de forma a impedir a articulação de focos de resistência ou de formação de opinião pública contrária ao regime. Tangidos pelo medo, os cidadãos deixam de formar grupos de conversação em público e, onde isso venha a acontecer, tende-se à despolitização dos diálogos, o que, na prática, constitui efetivo silenciamento político.

O controle absoluto da imprensa representa sobretudo a negação ao jornalismo de publicar a notícia que eventualmente não interesse ao regime. Nesses casos, multiplicam-se os atos de censura, por parte do Estado, e de autocensura, no interior das instituições de comunicação, sobre os profissionais e seu trabalho. A capacidade de resistência dos profissionais e dos próprios jornais à arbitrariedade do governo ditatorial é um dos fatores que melhor indica a fragilidade ou a força política do regime.

E, por fim, o fechamento dos parlamentos constitui, obviamente, o silenciamento político e jurídico da interlocução livre entre sociedade e Estado - e é uma das ações de arbítrio mais caracterizadoras do regime totalitário. Sem parlamento, a população não encontra, entre os políticos, o debate e a tomada de decisão sobre os quais ela poderia influenciar. 
Duas observações de acréscimo são necessárias, neste ponto. Primeiro, as ditaduras não podem se manter sem comunicação, apesar de serem, por definição, repressoras dos processos comunicacionais. A incomunicabilidade é fatal para qualquer regime, não importa qual seja, uma vez que é sabido em ciência política que todo regime, por mais fechado, tem que se apoiar em pelo menos um setor importante da sociedade. Não é possível ser ditador contra todos.

No que respeita aos processos comunicacionais, o raciocínio relativamente trivial é de que até para sustentar os recursos da tirania, o uso da linguagem deve se fazer presente de forma instrumental. Em termos simplificados, é preciso que escravo e senhor participem da mesma comunidade lingüística, ainda que apenas o suficiente para que regras, ordens e ameaças de punição sejam minimamente compreendidas.

A diferença entre a comunicação nos regimes autoritário e democrático, pois, é que, naquele, a comunicação é percebida apenas como meio para que se alcance os fins pretendidos, restando todas as demais formas sob suspeita, consideradas como ameaça ao regime. Nas democracias, em princípio, dá-se o contrário: mesmo que as razões e usos instrumentais e estratégicos da comunicação não estejam ausentes, é a sustentação e a proteção aos espaços de liberdade que determinam o gradiente de democraticidade do regime.

O tirano, pois, não pode fechar todos os jornais e encerrar a questão, pois o silêncio só até certo ponto o beneficia. O que ele deseja e exige até onde puder é o alinhamento, o elogio, a ausência de críticas. O que se silencia, no exercício do autoritarismo, são as vozes em contrário e, sobre as demais, busca-se estender o manto pesado do controle e da repressão, que variam conforme a força e o grau de totalitarismo que haja empiricamente.

A segunda observação diz respeito ao fato de que, mesmo nos regimes democráticos, elementos autoritários e até ilegítimos podem se fazer presentes, sem necessariamente se poder falar em ruptura da democracia. Aliás, faz parte da natureza específica do jogo democrático a pretensão de manter o autoritarismo sob regras, já que, pensando em termos racionais, seria excessivamente dispendioso e até indesejável democratizar tudo, no sentido de lançar todo exercício de vontade e toda decisão no âmbito da esfera pública, da fala coletiva, na busca do consenso ou do voto.

Entretanto, este aspecto específico e contraditório da relação entre liberdade e democracia poderá sempre ser legitimamente colocado em causa, sendo esta possibilidade - a da discussão sobre a regra, sua permanência ou sua alteração - aquilo que será o critério aferidor da condição democrática. Eis que surpreendemos, nesse ponto, algo importante para o objeto deste trabalho: os conflitos e contradições da democracia fazem parte do jogo democrático, sob estrita (porém ampla) condição de se estabelecerem como comunicação.

As liberdades fundamentais de expressão, de opinião e de negociação de sentidos para a ação são, pois, elementos fundamentais, caracterizadores do regime democrático. Tais liberdades podem estar presentes apenas parcialmente e em situações sociais específicas, sem caracterizar ruptura do regime democrático. Entretanto, sua ausência, ainda que parcial e limitada, pode implicar, neste caso, a inexistência de uma democracia plena e sólida.

É esse caráter relativo e relacional dos processos comunicativos na sociedade, aquilo que obriga o esforço teórico a pensar, como fizeram inúmeros autores, em "graus" de democratização, a partir das medição das condições de liberdade nos países em análise. Para os efeitos deste trabalho, pela mesma razão fala-se aqui em "gradiente de democraticidade", observando-se a democracia como processo, 
adotando-se a vertente qualitativa como método e se sugerindo a comunicação como categoria aferidora da democracia ou da democratização.

\section{Comunicação como política pública}

Pensada a comunicação como modo de ser da democracia e como garantia para o regime democrático, parece ter ficado clara a pretensão teórica deste trabalho: conferir a centralidade devida à comunicação, no trato das questões políticas, a partir do reconhecimento de que, em grande sentido, fazer política é fazer comunicação - fato que tem se tornado cada vez mais importante, quanto mais as tecnologias de comunicação penetram o cotidiano das pessoas e instituições. Espera-se igualmente ter ganho clareza a percepção de que esse axioma se torna ainda mais relevante, quando a temática política é a democracia, já que os vínculos deste regime com os processos de circulação da linguagem parecem ser muito mais fortes do que o são em outras formas de governo.

A sequência a esta linha de raciocínio é, então, a análise das responsabilidades institucionais do Estado e da sociedade política com as ações de comunicação. Se o vínculo da comunicação com a atividade política é assim tão extenso e profundo, torna-se conseqüência das mais simples esperar que as instituições democráticas - prioritariamente a estatal - assimile e assuma responsabilidades para com a preservação e o aprofundamento das bases comunicativas do regime democrático. Em outras palavras, exige-se o desdobramento institucional na forma de políticas públicas de comunicação.

A verdade, contudo, é que praticamente não existem políticas públicas de comunicação no Brasil e o próprio pensamento a respeito é muito recente, no país. Na realidade, é possível ir até mais além: a comunicação não é pensada por políticos e governantes na qualidade de uma política pública. Eis o motivo pelo qual se formula aqui o último corolário, que defende justamente essa qualidade. Comunicação é política pública e, como tal, deve ser pensada dentro da própria razão do Estado.

Há vários modos de se fazer isso. O que parece ser o mais claro e direto é pensar as diferentes concepções que os políticos, formuladores das políticas públicas, fazem do Estado, tomando como critério os resultados em termos de objetivos políticos, de cada uma dessas concepções. Nesse sentido, a imagem de um Estado pode ser:

a) Adversário. Trata-se do modo de ver o Estado, quando imperam os regimes totalitários e opressores. A herança brasileira de concepção do Estado, mesmo nos períodos democráticos, é bastante semelhante a esta, embora, neste caso, outras visões se façam presentes, de forma mais complexa. No Brasil, a herança colonial muito próxima parece ter construído uma acepção da instituição estatal como lugar de exploração e opressão, ante a qual é imperioso resistir, forma de pensar que talvez tenha contribuído para gerar o velho adágio latino-americano: "¿Hay gobierno? Jo soy contra”.

O Estado, visto como adversário, tem em si um único papel: o de gerar poder, capacidade suficiente de controle social, capaz de sustentar sua hegemonia, de forma violenta, se necessário. A idéia de opressão e seu oposto, a resistência, pacífica ou armada, é o fundamento desse modelo de Estado.

No campo da comunicação, as políticas específicas são igualmente repressivas: atuam no sentido de silenciar as oposições e determinar os conteúdos e formas dos processos e organizações de mídia. A comunicação neste sentido é muito mais um risco, a ser evitado e controlado, do que algo que se pareça de fato com uma "política de comunicação". 
b) Instrumento para alcançar outros fins. Trata-se de um modelo estratégicoinstrumental de Estado, mas, não no sentido sistêmico da palavra, de uso da instituição e de suas estruturas como meios para se alcançar os fins do Estado, que seria um modelo de tipo gerencial. Visto como instrumento para alcançar outros fins, a idéia é a de que os fins não são os do Estado, nem os da sociedade, e sim outras finalidades, de natureza privada e nem sempre cabíveis dentro das regras éticas e legais.

O Estado visto como instrumento desta forma é o Estado cujas políticas terminam por gerar exploração e corrupção. Visto como terra de ninguém, a instituição estatal é percebida como zona onde os impostos se transformam em dinheiro destinado a saques, pelos grupos de poder que o dominam. Qualquer semelhança destes elementos descritivos com realidades como a brasileira pode não ser mera coincidência.

No plano da comunicação, este tipo de Estado é gerador de ideologia, em seu sentido forte, como "falsa concepção da realidade". As ações e políticas de comunicação assim movimentadas visam sempre construir artificialmente a imagem dos governos, a fim de evitar que o uso arbitrário da instituição converta-se em escândalos e visibilidade pública da corrupção.

c) Prestador de serviços ou parceiro funcional. Trata-se do Estado gerencial ou administrativo, e assim visto, como campo de negociações de compra e venda de serviços estatais pelas organizações privadas, e fornecedor de bens e serviços públicos. Num quadro de democracia e ausência de corrupção elevada, este é o modelo que costuma prevalecer no meio político.

Percebido desta forma, o Estado adquire uma imagem dupla: a de cliente dos fornecedores privados de insumos e a de fornecedor dos cidadãos vistos como clientes. Em ambos os casos, a idéia que prevalece é a de que a instituição estatal viabiliza negócios e atende necessidades e demandas da sociedade.

As políticas de comunicação do Estado parceiro são usualmente ações de propaganda, destinadas a vender a imagem do governo e de seus serviços, como argumento de legitimação da gestão, frequentemente orientada para garantir ao grupo político instalado no poder a maximização das chances de vitória eleitoral, no próximo pleito.

d) Lugar de afirmação e produção da cidadania. Trata-se do que se poderia denominar Estado cidadão. Este modelo evidentemente não exclui o anterior, sendo muito comum que a atuação do Estado como parceiro possa ser analisada pelo viés da cidadania, para aferir até que ponto os direitos são respeitados, no instante mesmo em que serviços são prestados à população. Um Estado clientelista, por exemplo, parece-se muito com o modelo " $b$ ", mas pode ter boa parte da visão concernente ao modelo "c"; entretanto, não tem como haver resquícios relevantes deste modelo " $\mathrm{d}$ ".

Este Estado, à diferença dos demais tipos, realiza um tipo de política absolutamente especial: produz comunicação. Ao direcionar suas ações e relações para a valorização da cidadania, torna-se uma instituição protetora das liberdades e orientada para a obediência estrita à vontade do cidadão.

Para isso, políticas devem ser desenvolvidas no sentido de ampliar ao máximo as zonas de percepção e contato da população, devolvendo a ela condições de atendimento e realização, não apenas no campo dos serviços públicos, mas também no âmbito da organização social, do respeito rigoroso aos direitos humanos e da manutenção dos canais de diálogo dos grupos e instituições sociais entre si e destas com o próprio Estado. 
Numa rápida síntese, voltada para o desenvolvimento do pensamento da comunicação como política pública, esta pode ser categorizada, nos diferentes modelos de Estado citados, como

a) Estado como adversário (totalitário): A comunicação é risco a ser evitado e repressão para eliminação da oposição e alinhamento da mídia ameaçada de sobrevivência. O objetivo é não haver comunicação não permitida. O principal meio de comunicação é o aparato da política, legal ou secreta.

b) Estado como meio para outros fins (instrumental): A comunicação é instrumento de exercício de poder e de conversão ideológica. O objetivo é produzir a hegemonia da informação pretendida. O meio principal de comunicação é estabelecer uma relação com as instituições de mídia, por meio da qual se possa comprar/produzir o consenso midiático.

c) Estado como prestador de serviços (gerencial): A comunicação é meio de propaganda, voltada para a produção da imagem favorável. O objetivo neste caso é posicionar a administração na mídia, razão pela qual não é raro encontrar-se este modelo de Estado praticando as mesmas políticas de comunicação do modelo anterior.

d) Estado como lugar da cidadania (comunicativo): A comunicação é condição de relacionamento e accoutability. O objetivo é comunicativo, no sentido pragmático: obter participação e produção da opinião. Produzir esferas públicas, portanto, uma vez que é a esfera pública, com sua amplificação cada vez maior dos relacionamentos, sob a proteção do Estado, é o meio de comunicação politicamente mais adequado e eficiente, para garantir a permanência e a longevidade do Estado democrático e cidadão. Até porque a multiplicação as esferas públicas, no entorno do Estado, é justamente o que pode fornecer um profundo enraizamento dessas esferas - e, portanto, dos sujeitos de cidadania que dela fazem parte-nos órgãos estatais, custodiando-o e contribuindo para determinar as políticas públicas.

Nesse sentido, uma política de comunicação consistente com o modelo cidadão de imagem do Estado é uma política que configure, pelo menos, uma política pública específica, na qual os objetivos sejam, entre todos aqueles que configuram a cidadania participativa, em seu aspecto tanto "temático", quando "pragmático", viando a produção do máximo de comunicabilidade. No limite, trata-se de criar uma situação social, política, cultural e administrativa que favoreça a inversão da lógica do poder e do controle, na relação entre Estado (instituição por excelência de poder) e sociedade.

\section{Referências Bibliográficas}

HABERMAS, J. (1981) Teoría de la acción comunicativa V. I. Madrid : Taurus, 1984.

HABERMAS, J. (1981a) Teoría de la acción comunicativa V. II. Madrid : Taurus, 1987.

THOMPSON, John. (1998) A mídia e a modernidade: uma teoría social da mídia. Petrópolis, Vozes.

SANTOS, Boaventura de S. (1995) Pela mão de Alice: o social e o político na pósmodernidade. São Paulo: Cortez, 1996.

WEBER, Max. (1921) Economia e sociedade: fundamentos da sociologia compreensiva. Brasília: Edunb, 1991. 
RODRIGUES, Adriano. (1990) Estratégias da comunicação: questão comunicacional e formas de sociabilidade. Lisboa: Presença.

O'DONNEL, Guilhermo. Teoria democrática e política comparada. Dados, vol. 42, n. 4, Rio de Janeiro, 1999. http://www.scielo.br/scielo.php?script=sci_ arttext\&pid=S0011-52581999000400001\&lng=en\&nrm=iso\&tlng=pt (acesso em $18 / 01 / 2011$, às $22 \mathrm{~h} 20)$

SCHUMPETER, Joseph. (1942) Capitalism, Socialism and Democracy. New York, Harper, 1975.

PRZEWORSKI, Adam et alii (1996) What Makes Democracies Endure? In: Journal of Democracy, vol. 7, № 1, pp. 39-56.

DIAMOND, Larry; LINZ, Juan J.; LIPSET, Seymour M. (1990) Politics in Developing Countries. Comparing Experiences with Democracy. Boulder, Co., Lynne Rienner Publishers.

SARTORI, Giovanni. (1987) The Theory of Democracy Revisited. Chatham, Chatham House Publishers. 